\title{
Obstructive sleep apnoea in a puerperal patient with Hallermann- Streiff syndrome
}

\author{
T. Shiomi*, C. Guilleminault ${ }^{+}$, H. Izumi*, S. Yamada*, K. Murata\# ${ }^{\#}$ T. Kobayashi*
}

\begin{abstract}
Obstructive sleep apnoea in a puerperal patient with Hallermann-Streiff syndrome. T. Shiomi, C. Guilleminault, H. Izumi, S. Yamada, K. Murata, T. Kobayashi. (C)ERS Journals Ltd 1999.

ABSTRACT: A 26 yr old puerperal female with Hallermann-Streiff syndrome developed serious obstructive sleep apnoea syndrome during pregnancy. She underwent an elective Caesarean section delivery, but ending the pregnancy did not improve her clinical symptoms. By treating her with nasal continuous positive airway pressure, a worsening of her headaches and glaucoma was prevented. The administration of acetazolamide controlled all of her symptoms. Treatment with nasal ventilation is the best initial approach. It is also important to assure normal oxygenation before pregnancy since the foetus may suffer from the severe deprivation that may occur in these patients.
\end{abstract}

Eur Respir J 1999; 14: 974-977.

\author{
*Third Dept of Medicine, Aichi Medical \\ University, Aichi, Japan. ${ }^{+}$Sleep Research \\ Center, Stanford University School of \\ Medicine, Stanford, California. Dept of \\ Oral and Maxillofacial Surgery, Aichi \\ Medical University, Aichi, Japan. " Dept \\ of Radiology, Aichi Medical University, \\ Aichi, Japan.
}

Correspondence: C. Guilleminault, Sleep Disorders Center, 701 Welch Rd, Suite 2226, Palo Alto CA 94304 USA. Fax: 16507258910

Keywords: Continuous positive airway pressure, Hallermann-Streiff obstructive sleep apnoea syndrome, puerperal woman sleep apnoea

Received: May 181998

Accepted after revision February 281999
The essential clinical manifestations of HallermannStreiff syndrome (HSS) are craniofacial disproportion (bird-like face), bilateral congenital cataracts and bilateral microphthalmia. HSS is a congenital disease of unknown aetiology which is associated with proportionate nanism, hypotrichosis, atrophy of the skin and dental abnormalities [1]. The diagnostic criteria of Francois [2] are useful in the diagnosis of HSS, and it is easy to differentiate HSS from other diseases by noting the presence of congenital cataracts associated with mandibular hypoplasia producing a bird-like face at birth. Because the existence of intellectual disorders and cardiac diseases in HSS patients is relatively rare, medical treatment is almost unnecessary after patients reach adulthood, except for some ophthalmologic and cosmetic problems. Nonetheless, mandibular hypoplasia, micromastomia, beaked nose and abnormal dentition are significant causes of increased upper respiratory tract resistance in HSS patients [3-8]. This study reports an adult case of the syndrome.

\section{Case report}

The patient, a 26-yr-old Japanese female with a proportionate short stature was seen for complaints of easy fatigability, excessive daytime sleepiness, heavy snoring, gasping for air at night, and night sweating. She had been diagnosed with HSS at 6 months of age, and had been surgically treated for bilateral congenital cataracts. While at elementary school, she had also twice undergone surgery for glaucoma. At those times, following general anaesthesia, she had experienced respiratory arrest which necessitated resuscitation and had a difficult recovery with extended intubation. However, no doctor had associated her difficult post-anaesthesia complications with her birdlike face nor considered the possibility of sleep disordered breathing. Subsequently, she was prescribed acetazolamide orally for her glaucoma and completed her education at a special school for the visually handicapped. After high school graduation, she became a physiotherapist.

Her well-being worsened abruptly when she became pregnant at 25 yrs. She developed very significant daytime sleepiness that did not seem to remit after the first trimester. Simultaneously, her light snoring became very loud, and her breathing during sleep became laborious, with the presence of intermittent pauses after the 5th month of pregnancy. Her symptoms progressively worsened and an elective Caesarean delivery was performed after the 36th week of gestation. She delivered a low birth weight infant who needed immediate intensive care and transient intubation, with hospitalization in a neonatal intensive care unit (NICU) and intermediate intensive care unit (ICU) for the first month of life.

Despite delivery, the patient's clinical symptoms persisted. At examination, she was a, $137 \mathrm{~cm}, 32 \mathrm{~kg}$ female with a body mass index of $17 \mathrm{~kg} \cdot \mathrm{m}^{-2}$. She had not yet reached her prepregnancy weight of $30 \mathrm{~kg}$. She fulfilled all seven of the criteria of Francois [2] for diagnosis of HSS. She had dyscephalia and a bird-like face, dental anomalies, proportional nanism, hypotrichosis, atrophy of the skin, bilateral microphthalmia and congenital cataract (fig. 1). Her facial evaluation revealed mandibular hypoplasia and beaked nose due to maldevelopment of the nasal cartilages. Her blood pressure was 130/80 $\mathrm{mmHg}$. 
She had a nystagmus in the horizontal gaze and near blindness. Her cardio-thoracic ratio, estimated from her chest radiograph, was $45.2 \%$. No cardiovascular abnormality was present with normal electrocardiography (ECG) and echocardiography.
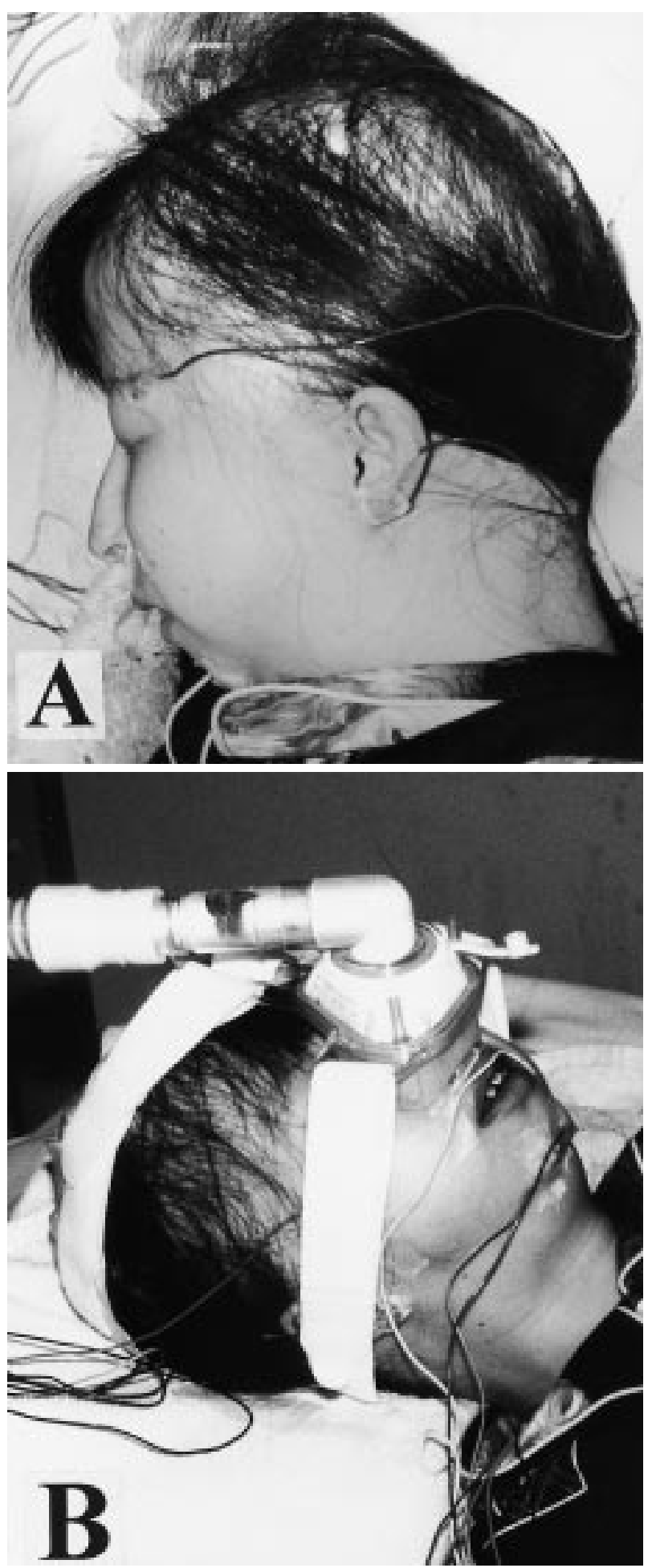

Fig 1. - Photographs of a patient with Hallerman-Streiff syndrome taken A) before and B) during nasal continuous positive airway pressure (CPAP) titration. Note dyscephaly with beak-shaped nose and micrognathia, and hypotrichosis.
Three weeks after delivery, her Epworth Sleepiness Scale score [9] (with exclusion of questions relating to driving) was $17 / 21$, and her nocturnal polysomnogram indicated a respiratory disturbance index of 82.3 apnoeas/ hypopnoeas $\cdot h$ sleep $^{-1}$, a low arterial oxygen saturation $\left(\mathrm{Sa}_{\mathrm{O}} \mathrm{O}_{2}\right)$ of $74 \%$, and $46.8 \%$ of the total sleep time (TST) spent with $\mathrm{Sa}_{\mathrm{a}} \mathrm{O}_{2}<90 \%$. Her nocturnal sleep was significantly disturbed with a sleep latency of $\sim 3 \mathrm{~min}$, a rapid eye movement (REM) sleep latency of $61 \mathrm{~min}$, and a complete absence of stage 3 and 4 non rapid eye movement (NREM) sleep, with 59\% NREM sleep in stage 1. Her arousal index was 118.4 events.h sleep ${ }^{-1}$ [10]. This was due to the presence of respiratory events $<10 \mathrm{~s}$ that disturbed her sleep even further. In summary, she had a very severe obstructive type of sleep disordered breathing.

Figure 2 shows cephalometry and magnetic resonance images (MRI) of the neck taken by the spoiled gradient recalled acquisition in a steady state (SPGR) technique. Cephalometry revealed marked reduction of the anteroposterior diameter of the mandible, as well as diminution in the maxillary bone, ascending ramus of the maxilla, and the dental arch length of the upper and lower jaws which were similar to those of a 5-yr-old child. The sella-nasion distance was $59.5 \mathrm{~mm}$ versus a mean $\pm \mathrm{SD}$ of $68.4 \pm 2.4 \mathrm{~mm}$ in age-matched control Japanese females [11]. Moreover, there was a conspicuous constriction extending from the nasopharnyx to the oropharynx. Although the distance from posterior nasal spine to tip of soft palate (PSN-P) was $30.5 \mathrm{~mm}$ (the mean \pm 1 sD in Japanese females of a matching age is $37 \pm 3$ $\mathrm{mm},[11])$, the palatine uvula appeared large as seen from the size of the oral cavity. The lateral wall of the nasal cavity was extremely narrow with a posterior airway space (PAS) of $4.0 \mathrm{~mm}$. (mean $\pm 1 \mathrm{sD}$ is $11 \pm 1 \mathrm{~mm})$, and the size of the airway under the palatine uvula was $\sim 1 \mathrm{~mm}$, i.e., a state of almost complete occlusion. The distance from the hyoid to mandibular plane (MP-H) of 32.0 was elongated (mean \pm 1 SD is $15.4 \pm 3 \mathrm{~mm}$ [11]). Furthermore, MRI also demonstrated dorsolateral deviation of the tongue due to hypoplasia of the mandible, as well as significant narrowing of the oropharynx by the base of the tongue. During inspiration, while supine, a complete occlusion of the oropharynx was seen (fig. 2).

Emergency treatment with nasal continuous positive airway pressure (CPAP) was initiated. Positive pressure of $7 \mathrm{cmH}_{2} \mathrm{O}$ eliminated the polygraphic abnormalities. At polygraphic recording, the apnoea-hypopnoea index was 7 events $\cdot \mathrm{h}^{-1}$. The mean oxygen saturation was just above $97 \%$ and the lowest $\mathrm{Sa}_{2} \mathrm{O}_{2}$ was $93 \%$. She had a drastic reduction of stage 1 NREM sleep despite limited habituation to nasal CPAP $(17 \%)$ and reappearance of stages 3 and 4 NREM sleep (9\%). A dramatic clinical improvement was seen within $24 \mathrm{~h}$. On day 3 , however, the patient complained of morning headache and occular pain. Her glaucoma also seemed to worsen. The possibility that nasal CPAP had a role in the appearance of the symptoms was discussed. However, since acetazolamide had been interrupted at the time of delivery due to lactation, it was decided to permit nasal CPAP treatment with daily supervision and the administration of acetazolamide 500 $\mathrm{mg} \cdot$ day $^{-1}$. The patient has since returned to normal life under the combined treatment. 

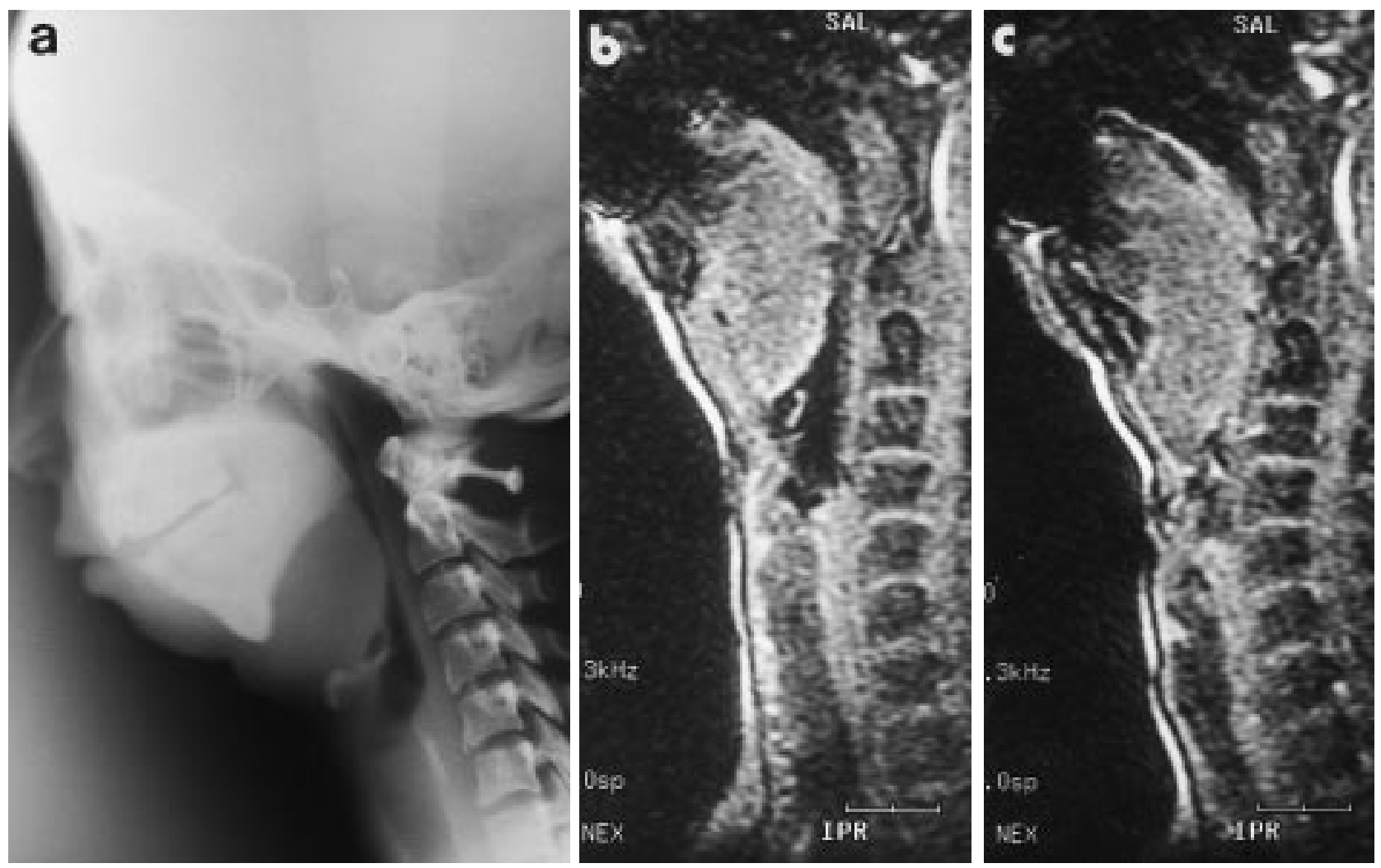

Fig 2. - Lateral cephalogram and magnetic resonance images (MRI) (b and c) of the neck taken by the spoiled gradient recalled acquisiton in a steady state (SPGR) technique. Note the hypoplastic mandible and the narrow airway. Particularly during inspiration, a complete occlusion of the oropharynx is shown on the MRI (c).

Very long term follow-up was not available, but 2 months post-delivery the patient, when not using nasal CPAP for one night, presented with abnormal breathing with the presence of obstructive hypopnoeas and a low $\mathrm{Sa}_{\mathrm{a}} \mathrm{O}_{2}$ of $84 \%$.

\section{Discussion}

The case report is of heuristic value for several reasons. HSS, described 50 yrs ago, is a rare congenital syndrome of unknown aetiology. It is of low incidence. One survey of birth prevalence of congenital anomalies in Japan found only a single case of HSS among 27,472 consecutively born infants [12]. The syndrome involves micrognathia and craniosynostosis, as seen in Pierre Robin, Crouzon, and Apert's Syndromes. Obstructive sleep apnoea syndrome (OSAS) has been noted previously by FRIEDE et al. [4] in two individuals with severe HSS. Despite the fact that tracheostomy has been the recommended treatment since the early 1960s, nasal CPAP (or possibly nasal bilevel positive pressure ventilation if there are difficulties with CPAP) should be considered first.

RYAN et al. [7] have previously reported a complete resolution of symptoms with a return to normal growth in an 8-yr-old HSS female who underwent nasal CPAP treatment. However, Romeo et al. [6] reported a newborn with HSS whose OSAS was successfully treated initially with CPAP, but who later developed an upper airway infection and died on day 61. Newborn infants with severe micrognathia are indeed fragile, and considering the amount of time spent asleep, application of the nasal mask will be needed for much of the day. The classic risks associated with HSS are laborious breathing, pulmonary infections, OSAS and post-anesthesia respiratory arrest [1]. The decision concerning the best therapeutic approach to follow is, therefore, difficult when the affected subject is a newborn. Considering the risks associated with chronic tracheostomy in the newborn and the authors' own experience with nasal CPAP/bilevel positive airway pressure in very young infants, nasal ventilation should be selected as a first approach but with these very fragile infants kept in hospital care for the first 2-3 months [13]. Temporary intubation with mechanical ventilation for 2-3 days may be of assistance if infection occurs.

The present case report emphasizes that borderline cases will easily decompensate, even in adulthood. Females with craniofacial malformations and normal intelligence, such as those with HSS, have a much greater chance of becoming pregnant than subjects with other dysmorphia and significant mental retardation $[14,15]$. Even if cosmetic surgery has been performed, it does not mean that the upper airway has been appropriately enlarged (in the authors' experience, it rarely reaches normal size). Decompensation during sleep while pregnant is a significant risk, and the uncontrolled OSAS may be harmful to the mother and the foetus, which was probably the case here [16].

At short term follow-up, the patient had not returned to normal breathing. This may be related to the persistence of weight increase ( $2 \mathrm{~kg}$ compared to prepregnancy weight). 
It may be that, as seen in certain post-trauma or whiplash patients [17], the external event (here the pregnancy) led to abrupt decompensation of a very borderline equilibrium. The months of snoring and abnormal breathing may have permanently modified the upper airway to the point that return to this unstable equilibrium is impossible. Only long term (several yrs) follow-up with continuous treatment can provide answers.

Finally, the question of a possible role of positive pressure in the appearance of the morning headache and ocular pain should be considered. Undoubtedly, the patient had glaucoma, and the withdrawal of acetazolamide intake may have been a factor. Nasal continuous airway pressure has never been implicated, up to now, in worsening glaucoma. Reports of this association in young subjects with obstructive sleep apnoea syndrome are nonexistent. Only systematic collection of data from patients with such an association will help resolve the issue. It is possible that there could be some relationship between complaints of headaches and nasal continuous positive airway pressure in patients with severe craniofacial malformations. Reports of discomfort are also of concern, because this is a cause of noncompliance with treatment. The resolution of all symptoms with intake of acetazolamide has led the authors to retain the prescribed treatment [18]. However, the presence of such complaints indicates the need for regular follow-ups, which have been scheduled.

Acknowledgements. The authors thank R. Sasanabe and $\mathrm{K}$. Watabe of the Aichi Medical University, Third Department of Medicine and $\mathrm{T}$. Imamura of the Aichi Medical University. Department of Oral and Maxillofacial Surgery for their technical assistance and very useful comments.

\section{References}

1. Cohen MM. Jr, Hallermann-Streiff Syndrome: A review. Am J Med Genet 1991; 41: 488-499.

2. Francois MJ. A new syndrome: Dyscephalia with bird face and dental anomalies, nanism, hypotrichosis, cutaneous atrophy, microphthalmia and congenital cataract. Arch Ophthalmol 1958; 60: 842-863.

3. Falls ET, Schull WJ. Hallermann-Streiff syndrome: A dyscephaly with congenital cataracts and hypotrichosis. Arch Ophthalmol 1960; 63: 409-420.

4. Friede H, Lopata M, Fisher E, Rosenthal IM. Car- diorespiratory disease with Hallermann-Streiff syndrome: Analysis of craniofacial morphology by cephalometric roentgenograms. J Craniofac Genet Dev Biol (Suppl.) 1985; 1: 189-198.

5. Robinow M. Respiratory obstruction and cor pulmonale in the Hallermann-Streiff syndrome. Am J Med Genet 1991; 41: 515-516.

6. Romeo MG, Betta P, Rodono A, et al. A case of Hallermann-Streiff syndrome with rapidly fatal course. Pediatr Med Chir 1995; 17: 365-368.

7. Ryan CF, Lowe AA, Fleetham JA. Nasal continuous positive airway pressure (CPAP) therapy for obstructive sleep apnoea in Hallerinann-Streiff syndrome. Clin Pediatr 1990; 29: 122-124.

8. Van Balen ATM. Dyscephaly with microphthalmos, cataract and hypoplasia of the mandible. Ophthalmologica 1961; 141: 53-63.

9. Johns MW. A new method for measuring daytime sleepiness: The Epworth Sleepiness Scale. Sleep 1991; 14: 540-545.

10. American Sleep Disorders Association of the EEG Arousals. Atlas Task Force: Scoring Rules and Examples. Sleep 1992; 15: 173-184.

11. Ishikawa F. Roentgenographic cephalogram. In: Iizuka T, Ishikawa F, Sato M, Sluzuki S, eds: Orthodontics (in Japanese) Tokyo, Quintessence, 1989; pp. 105-123.

12. Higurasi M, Oda M, Iijima $\mathrm{K}$, et al. Livebirth: prevalence and follow-up of malformation syndrome in 27,472 newborns. Brain Dev 1990; 12: 770-773.

13. Guilleminault C, Pelayo R, Clerk A, Leger D, Bocian RC. Home nasal continuous positive airway pressure in infants with sleep-disordered breathing. J Pediatr 1995; 127: 905-912.

14. Cabral CFJ, Orozco QM, Ibaguengoita OF, Cargallar GL, Karchmer S. Hallermann-Streiff syndrome and pregnancy. A case report. Ginec Obstet Mex 1994; 62: 207-210.

15. Hendrix SL, Sauer HJ. Successful pregnancy in a patient with Hallermann-Streiff syndrome. Am J Obstet Gynecol 1991; 164: 1102-1104.

16. Charbonneau M, Falcone T, Cosio MG, Levy RD. Obstructive sleep apnoea during pregnancy: therapy and implications for fetal health. Am Rev Respir Dis 1991; 144: 461-463.

17. Guilleminault C, Faull K, Miles L, Van den Hood Y. Post traumatic excessive daytime sleepiness: A review of 20 patients. Neurology 1983; 33: 1584-1589.

18. Whyte KF, Gould GA, Airlie AA. Role of protriptyline and acetazolamide in the sleep apnoea/hypopnea syndrome. Sleep 1988; 11: 463-472. 